\title{
A LEXICON OF DISTRIBUTED NOUN REPRESENTATIONS CONSTRUCTED BY TAXONOMIC TRAVERSAT,
}

\author{
Richard F.E. Sutcliffe', Donie O'Sullivan, Fergus Meharg \\ Department of Computer Science and Information Systerns \\ University of Timerick, Ireland
}

\section{IN'TIRODUC'ITON}

In order to construct systems which can process natural language in a sophisticated fashion it is highly desirable to be able to represent linguistic meanings in a computationally tractable fashion. One approach to the problem of capturing neanings at the lexical level is to use a form of distributed representation where each word meaning is converted into a point in an $n$-dimensional space (Sutcliffe, 1992a). Such representations can capture a wide varicty of word meanings within the same formalism. In addition they can be used within distributed representations for capturing higher level information such as that expressed by sentences (Sutcliffe, 1991a). Moreover, they can be scaled to suit a particular tradeoff of specificity and memory usage (Sutclifle, 1991b). F'inally, distributed representations can be processed conveniently by vector processing methods or connectionist algorithms and can be used either as part of a symbolic system (Sutcliffe, 1992b) or within a connectionist architecture (Sutcliffe, 1988). In previous work we have shown how such representations can be constructed autonatically by the method of taxonomic traversal, using the Merriam Webster Compact Wlectronic dictionary (Sutcliffe, 1993) and the Irish-Irish $\Lambda_{\mathrm{n}}$ Foclóir Beag (Sutclifle, Mcrlligott and Ó Néill, 199:3). However our efforts so far have been limited by our parsing technology to lexicons of a few thousand words. We describe here how we can generate a lexical entry for any of the 71,000 nouns $^{2}$ in the P'rinceton WordNet (Beckwith, lellbaum, Gross and Miller, 1992), and the initial tests we have conducted on the representations.

Our method is closely related to other work which exploits the taxonomic nature of diclionary definitions (Anster, 1980; Fiedorn, Byrd and Chodorow, 1986; Vossen, 1990; Guthrie, Slatior, Wilks and Bruce, 1990; Nutter, fox and Fvens, 1990). In addition there have alrcady been some very intoresting approaches to the construction of distributed semantic representations either from dictionaries (Wilks et al, 1990) or from corpora (Schuctze, 1993).

\footnotetext{
${ }^{1}$ This research was supported in part by the Enropean Union under contract I,RE-62030 and by the National Software Directorate of Ireland. We are indelsted to I'ony Molloy, Redunomel O'Brien and Gemmat Ryan for their help with this work.

${ }^{2}$ This figure includes hyphenated terms, compound nouns and proper names,
}

\section{EXTRACITNG FEATURE REPRESEN- TATIONS}

The object of our work is to produce for each nounsense in a lexicon a semantic representation consisting of a set of feature-centrality pairs. 'The features are semantic attributes each of which says something about the concept being refined. The centrality associaled with each feature is a roal number which indicates how strongly the feature contributes to the meaning of the concept. 'The use of centralities allows us to distinguish between important and less importint features in a semantic representation. By scaling the centralities in a particular noun-sense representation so that the sum of their squares is one we can use the dot product operation to compute the seman tic similarity of a pair of concepts. A word compared to itself always scores one while a word compared to another word is always less than or equal to one. 'I'his is equivalent to saying that each word representation is a vector of length one in an $n$-dimensional space, where $n$ is the number of features which are used in the lexicon as a whole.

Our algorithm for constructing the representations is based on two well-known observations. Firstly, a word definition in a dictionary provides attribute information about the concept ('a mastifl' is a I, $\mathrm{ARG}$ ' dog'). Secondly a word (lefinition also provides taxonomic infornation about the concept ("a mastiff is a large DOC'). We use the former to derive attributes for our representation, and the latter to obtain other definitions higher up in the taxonomy from which fur ther attributes can be obtained. In assigning centralities to features, we use the same value for each attribute added at a particular level in the taxonornic hierarchy, and we reduce the value used as we move up to higher levels. 'This corresponds to the intuition that a feature which is derived from a definition which is close to the word of interest in the taxonomy contributes more to its meaning than one which is derived from a tuore distant definition.

'The Princeton WordNet is very suitable for use in implementing our extraction algorithm because taxo nomic links are represented explicitly by pointers. In most MRIDs such links have to be deduced by syntactic and semantic analysis of sense definitions. Nouns in WordNet are organised around synsels. liach synset may include a list of synonyms, pointers to hyponym and hypernym synsets, and a gloss corresponding to a conventional dictionary definition. 
Figure 1. Synset Hierarchy for the word 'terrier' derived from Princeton Wordnet.

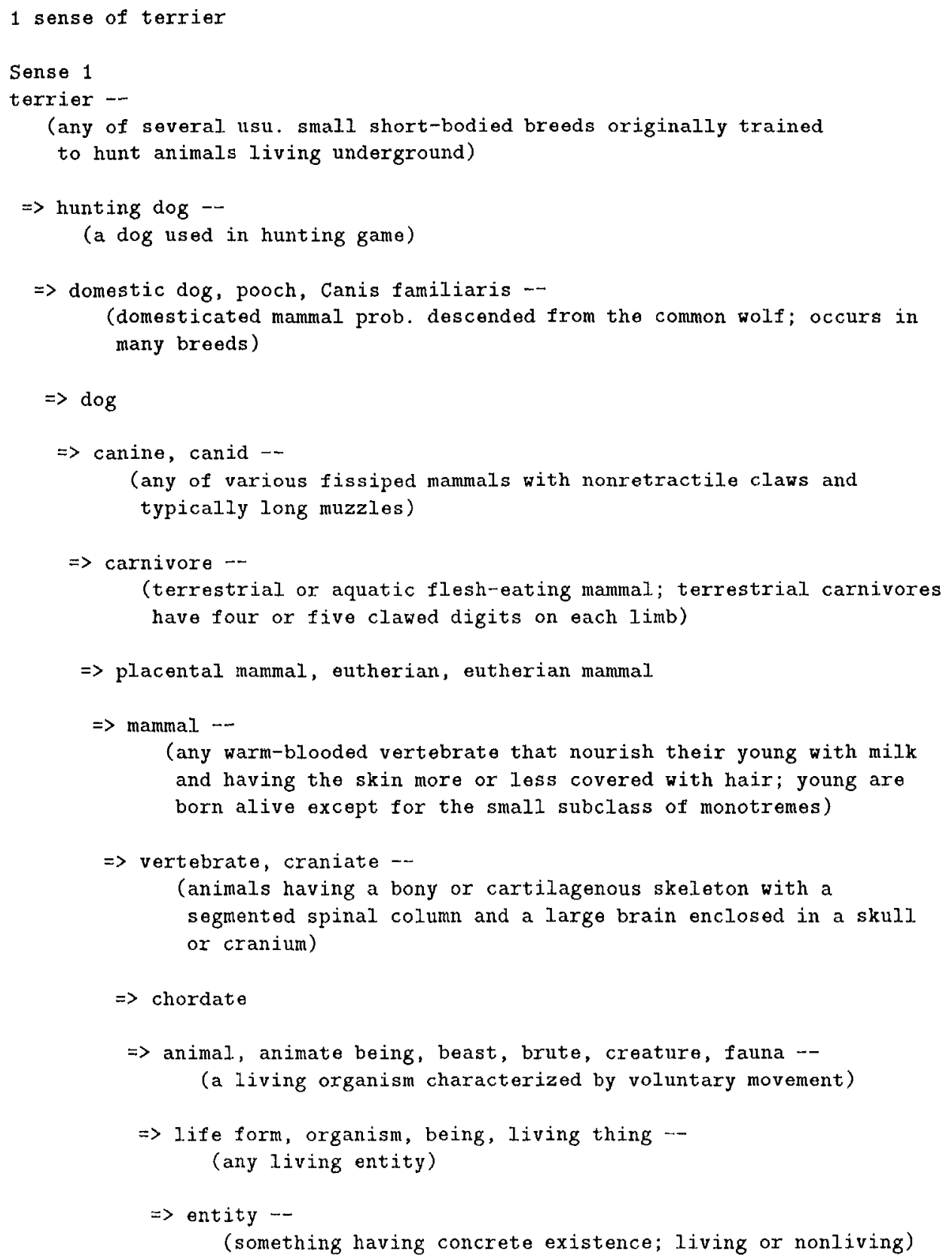




\begin{tabular}{|c|c|c|c|c|}
\hline cars & dogs & flowers & trees & people \\
\hline $\begin{array}{l}\text { chariot } \\
\text { motorlike } \\
\text { jecp } \\
\text { moped }\end{array}$ & $\begin{array}{l}\text { pug } \\
\text { terrier } \\
\text { lapdog } \\
\text { chihuahua }\end{array}$ & $\begin{array}{l}\text { pantiy } \\
\text { dafforlil } \\
\text { tulip } \\
\text { rose }\end{array}$ & $\begin{array}{l}\text { letch } \\
\text { pine } \\
\text { oak } \\
\text { sycatnore }\end{array}$ & $\begin{array}{l}\text { bruiser } \\
\text { patriarch } \\
\text { siren } \\
\text { rake }\end{array}$ \\
\hline
\end{tabular}

The extraction algorithm starts with the synsel colresponding to the word-sense for which we wish to create a lexical entry. The gloss is tokenised, function words are removed and the remaining content words are converted to their root inflection. All such words are considered to be fcatures of the word-sense, and are given a centrality of 1.0 . We then chain upwards using a hypernymic link (if any) ${ }^{3}$. At the next level up, features are extracted from the hypernym's gloss, using a contrality of 0.9 . The process is repeated, reducing the centrality by 0.1 at each level, until either the top of the hicarchy is reached or the centrality falls to zero. Finally, the representation, consisting of a sel of feature-centrality pair's, is normalised.

\section{IRESUITS}

The algorithm described above has been implenented and can be used to construct a lexical entry lor any of the nouns in the WordNet database. rigure 1 shows the synset hypernym hierarchy for the word 'terricr' in WordNet. Figure 2 shows the semantic representation derived by the algorithm for this word. We present, here some preliminary experiments which attempt to measure the performance of the lexicon. Four words were chosen from each of five categories of noun which we label cars, logs, flowers, trees and people. These are shown in 'Table 1 . Table 2 shows a summary of the characteristics of the word representations in the set of twenty words. Pairs of categories were chosen, cars-dogs, flowers-trees and so on, each containing eight words. A series of eight-by-eight tables was then computed, showing the dot product of each word with every other word in the category pair. Table 3 shows the results for the cars-dogs matrix. There are several points to note about this table. Firstly, the match of onc car word with another is high, ranging between 0.58 and 1.0 with an average of 0.8 . 'This shows that the lexicon has captured the similarity between the car concepts. Secondly, the match of one dog word with another is also high, ranging between 0.63 and 1.0 with an average of 0.76 , for the same reason. Thirdly, the match of a car work with a dog word is low, ranging between 0.05 and 0.17 with an average of 0.1 . 'This is because cars and dogs are not closely linked semantically. 'Table 4 shows results for the flowers-trees matrix. Flowers and trees are much more closely related scmantically than cars and dogs, and this is reflected in the results. Flower words match with tree words in a range of 0.30 to 0.67

\footnotetext{
${ }^{3}$ At present. we only choose the first such link if there are
} several.

\begin{tabular}{|lr|}
\hline Table 2. Lexical Representation Summary \\
\hline No of words & 20 \\
Total number of features & 249 \\
Average number of features & 39 \\
Minimum & 17 \\
Maxinum & 76 \\
\hline
\end{tabular}

with an average of 0.4 , much higher than for ears and clogs. 'The match of flowers with flowers or trees with trees continues to be high. Finally, Table 5 shows the people-dogs matrix. Note liere that the matel of people with themselves is lower than that of dogs with thenselves (average 0.63 rather than average 0.76 .) 'This is becaluse the people words are in fact a rather disparate set. Note in particular that 'bruiser' against 'rake' is the best match while 'bruiser' against 'patriarch' is the worst. 'This matches one's intuitions about these concepts: patriarchs are "good" while 'bruisers' and 'rakes' are not.

\section{CONCLUSIONS}

We have presented a simple algorithm which allows a set of distributed lexical semantic representations to be constructed from noums in the P'rinceton WordNet. The results show that the method works and produces good results. The main rcason for this is the explicit taxonomic information in WordNet which has to be inferred in other dictionaries. Incorrect taxonomic information seriously degrades the performance of this kind of method. On the other hand errors in individual features are not so harmful as they have no knock-on effects. However, we are engaged in eliminating errors in word sense and syntactic eategory which are the principal sontes of inaccuracy in the method. In addition we are working on objective methods for measuring the performance of the lexicon on a large scale.

\section{REFERTINCES}

Amster, R.A. (1984). Machine-Readable Dictionaries. Annual Revicw of Information Science and 'Technology (ARIST), 19, 161-209..

Beckwith, R., Fellbaum, C., Gross, 1)., \& Miller, G.

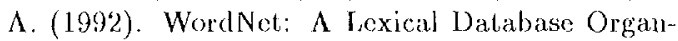
ised on Psycholinguistic P'rinciples. In U. Zernik (1;d.) Using On-line Resources to Build a hexicon. Ilillsdale, NJ: Lawrence Grlbaum $\Lambda$ ssociates.

Fvens, M. (1989). Computer-Readable Dictionaries. Annual Review of Information Science and Technology (ARIS'l), 24, 85-117.

Guthrie, I, Skator, B.M, Wilks, Y. and Bruce, R. (1990), Is there Content in Lmpty Heads? In Iroccedings of the 13 th International Conference on Compulational Linguistics (COLING-90), IIclsinki, finland, 3, 138-143.

IIicdom, Byrd and Chodorow (1986).

Lesk, M. (1986). Automated Word Sense Disambiguation using Machine-Readable Dictionaries: 


\begin{tabular}{|c|c|c|c|c|c|c|c|c|}
\hline & chariot & motorbike & jeep & moped & pug & terrier & lapdog & chihuahua \\
\hline chariot & 1.00 & 0.74 & 0.58 & $0 . \overline{7} 3$ & 0.13 & 0.17 & 0.14 & 0.09 \\
\hline motorbike & 0.74 & 1.00 & 0.69 & 1.00 & 0.11 & 0.11 & 0.11 & 0.06 \\
\hline jeep & 0.58 & 0.69 & 1.00 & 0.68 & 0.08 & 0.09 & 0.09 & 0.05 \\
\hline moped & 0.73 & 1.00 & 0.68 & 1.00 & 0.10 & 0.10 & 0.11 & 0.05 \\
\hline pug & 0.13 & 0.11 & 0.08 & 0.10 & 1.00 & 0.68 & 0.65 & 0.69 \\
\hline terrier & 0.17 & 0.11 & 0.09 & 0.10 & 0.68 & 1.00 & 0.63 & 0.72 \\
\hline lapdog & 0.14 & 0.11 & 0.09 & 0.11 & 0.65 & 0.63 & 1.00 & 0.67 \\
\hline chihuahua & 0.09 & 0.06 & 0.05 & 0.05 & 0.69 & 0.72 & 0.67 & 1.00 \\
\hline
\end{tabular}

\begin{tabular}{|lllll|lll|}
\hline Table 4. Flowers vs. Trees & & & & \\
\hline
\end{tabular}

Table 5: People vs. Dogs

\begin{tabular}{|lllll|llll|}
\hline & bruiser & patriarch & sireal & rake & pug & terrier & lapdog & chihuahua \\
\hline bruiser & 1.00 & 0.40 & 0.52 & 0.63 & 0.12 & 0.15 & 0.13 & 0.08 \\
patriarch & 0.40 & 1.00 & 0.40 & 0.55 & 0.15 & 0.18 & 0.16 & 0.17 \\
siren & 0.52 & 0.40 & 1.00 & 0.50 & 0.14 & 0.17 & 0.14 & 0.09 \\
rake & 0.63 & 0.55 & 0.50 & 1.00 & 0.12 & 0.15 & 0.13 & 0.08 \\
\hline pug & 0.12 & 0.15 & 0.14 & 0.12 & 1.00 & 0.68 & 0.65 & 0.69 \\
terrier & 0.15 & 0.18 & 0.17 & 0.15 & 0.68 & 1.00 & 0.63 & 0.72 \\
lapdog & 0.13 & 0.16 & 0.14 & 0.13 & 0.65 & 0.63 & 1.00 & 0.67 \\
chihuahua & 0.08 & 0.17 & 0.09 & 0.08 & 0.69 & 0.72 & 0.67 & 1.00 \\
\hline
\end{tabular}

repn( terrier, '(any of several usu. small short-bodied breeds originally trained to hunt animals 1 iving underground)', [[any, 0.19], [several, 0.19], [small, 0.19], [breed, 0.19], [originally, 0.19], [trained,0.19], [hunt, 0.19], [animal, 1.9], [living, $0.19]$, [underground, 0.19], [a, 0.17], [dog, 0.17], [used, 0.17], [in, 0.17], [hunting, 0.17], [game, 0.17], [domesticated, 0.15], [mammal, 0.15], [descend, 0.15], [common, 0.15], [wolf, 0.15], [occur, 0.15], [many, 0.15], [various, 0.11], [fissiped, $0.11]$, [with, 0.11], [nonretractile, 0.11], [claw, 0.11], [typically, 0.11], [long, $0.11]$, [muzzle, 0.11], [terrestrial, 0.096], [aquatic, 0.096], ['flesh-eating', 0.096], [carnivore, 0.096], [have, 0.096], [four, 0.096], [five, 0.096], [clawed, 0.096], [digit, 0.096], [on, 0.096], [each, 0.096], [limb, 0.096], ['warm-blooded', 0.057], [vertebrate, 0.057], [nourish, 0.057], [young, 0.057], [milk, 0.057], [skin, 0.057], [more, 0.057], [less, 0.057], [covered, 0.057], [hair, 0.057], [are, 0.057], [born, 0.057 ], [alive, 0.057], [except, 0.057], [monotreme, 0.057], [bony, 0.038], [skeleton, 0.038 , [segment, 0.038], [spinal, 0.038], [column, 0.038], [large, 0.038], [brain, 0.038 , [enclosed, 0.038], [skul1, 0.038], [cranium, 0.038], [organism, 0.01], [characterized, 0.01], [voluntary, 0.01], [movement, 0.01], [entity, 0.01], [concrete, $0.01]$, [existence, 0.01], [nonliving, 0.01]] ).

Figure 2. The semantic representation for 'terricr' produced by the algorithm. 
How to 'lell a Pine Cone from an Ice (rean Cone. Proceedings of the 1986 SIGDOC Conference.

Ide, N.M. and Voronis, J. (1990). Very Largo Nenral Networks for Word Sense Disambiguation. Procedings of the Huropean Conference on Artificial Intelligence, l'CAI'90, Stockholm, August 1990.

Miller, G.A., Beckwith, R., Christianc Fellbaum, Gross, D. and Miller, K. (1992). Introduction to WordNet: An On-line I,exical Database. Manuscript.

Nutter, J.T', Fox, E.A. and Fvens, M.W (1990). Building a Lexicon from Machine Readable Dictionaries for Improved Information Retrieval. literary and Linguistic Computing, 5, 2, 129-138.

Schuetze, II. (1993). Translation by Confusion. In Procedings of the AAA1-93 Spring Symposium Scries: Building Lexicons for Machine Translation, March 23-25, 1999, Stanford, University, CA.

Sharkey, N.E., Day, P.A. and Sharkey, A.J.C. (1991). $\Lambda$ Connectionist Machine Tractable Dictionary: The Very Idea. In C.-M. Guo (lid.) Machine Rearlable Dictionaries. Norwood, NJ: $\Lambda$ blex.

Sutcliffe, R.F.l'. (1988). A Parallel Distributed Processing $\Lambda$ pproach to the Representation of Knowledge for Natural Lamguage Undersbanding. Unpublished doctoral thesis, University of Hssex, UK.

Sutcliffe, R.F.L. (199la). Distributed Representations in a 'Text Based luformation Retrieval System: $\Lambda$ New Way of Using the Vector Spawe Model. In Proceedings of the l'ourteenth Annual International ACM/SIGIR Conference on Research and Development in Information Retrieval, Chicago, H., October 13-16, 1991. New York, NY: ACM Press, pl. 123-132.

Sutcliffe, R.P.ls. (1991b). Distributed Subsymbolic Representations for Natural Language: How many Features Do You Need? Proceedings of the 3rd Irish Conference on Artificial Intellagence and Cognitive Sicience, 20-21 September 1990, Uninersity of Olster at Jordanstown, Northern Ireland. Berlin, FRG, Heidelberg, FlkG, New York, NY: Springer Verlag.

Sutcliffe, R.F.F. (1992a). Representing Meaning using Microfeatures. In R. Reilly and N.F. Sharkey (eds) Connectionist Approaches to Natural Language Processing. linglewood Clifls, NJ: Lawrence Erlbaum Associates.

Sutcliffe, R.F.F. (1992l)). PFHICAN: A Prototype Information Retrieval System using Distributed Propositional Representations. 'T'o Appear in $\mathrm{L}$. Sorensen (Wd.) Procedings of AICS-91 - The lourth Irish Conference on Artificial Intelligence and Cognitive Science, University College Cork, 19 . 20 September 1991. I,ondon, UK, Berlin, IRG, IJcidelberg, FGR, New York, NY: Springer-Vorlag.

Sutcliffe, R. F. E. (1993). Constructing Distributed Scmantic Lexical Ropresentations using a Machine Readable Dictionary. In K.'T. Ryan and R. I'. Li. Sulcliffe (Lids.) Procedings of AICS-9I - The
I'ifth lrish Conference on Artificial Intelligence and Cognitive Science, University of Limerick, $10-11$ September 1992. Iondon, UK, Berlin, FRG, Heidelberg, liGR, New York, NY: Springer-Verlag.

Sutcliffe, R. F. E., Mckilligott, A., \&. O'Neill, G. (1993). Using Distributed Patterns as I anguage Independent Lexical Representations. In Proceedings of the AAAI-9B Spring Symposium Series: Building Lexicons for Machine Translation, March 23 255, 1993, Stanforl, University, CA.

Vossen, P'. (1990). 'The Find of the Chain: Where Does Decomposition of Lexical Knowledge Iead us Eventually? lisprit B1RA-3030 ACQUIIEX WP 010. Hinglish Department, University of $\Lambda$ msterdam, 'I'he Netherlands.

Wilks, Y., Fass, D., Guo, C.-M., Macdonald, J., Plate, 'I'. and Slator, B. (1990). Providing Machine Tractable Dictionary Tools. Machine Translation, $5,99-154$.

\begin{tabular}{|c|c|}
\hline \multicolumn{2}{|c|}{ Fable o Word-Word Summary } \\
\hline Cars-Cars average & 0.80 \\
\hline Cins-I)ogs average & 0.10 \\
\hline Dogs-l)ogit average: & 0.76 \\
\hline Hlowers-Flowers average: & 0.58 \\
\hline T'rees- J'lowers average: & 0.40 \\
\hline 'l'rees-Trees average & 0.78 \\
\hline ['eople l'eople average & 0.63 \\
\hline Dogs-1)ogs average & 0.76 \\
\hline People-])ogs average & 0.14 \\
\hline
\end{tabular}

